\title{
Preventive Imperatives among Correlative Meanings
}

\author{
Alevtina A. Kalinina \\ Elena P. Kartashova \\ Mari State University, Yoshkar-Ola, Russia \\ Email: kalinina.07@inbox.ru
}

\section{Doi:10.5901/mjss.2015.v6n3s7p65}

\section{Abstract}

The article considers structures having the meaning of prevention. Some debatable questions in the interpretation of this type of semantics and linguistic means of its expression by supporters of different scientific trends make the article topical. The objective of the study is to reveal semantic specifics of the preventive imperative and differentiate it from a number of related constructions (with the meaning of caution, threat and fear) and also from prohibitive forms and optative constructions. A descriptive method, being used within the framework of structural-semantic approach, has been used as a leading one in the present article but with a greater attention to the semantic side of the phenomenon than it is customary in grammatical research. Thus, we support grammatical approach and justify its use for analysing the constructions under discussion. As a result, we tried to create a semantic model of a preventive utterance as a complex of correlative meanings forming an indivisible semantic unity and getting a synthetic expression in the structure of the sentence. Special attention has been given to the semantic importance of the negation in the structure of the preventive imperative. The material of the article and its results may be useful for further research in the semantic area under discussion.

Keywords: imperative constructions, constructions with warnings, semantics of the prohibitive imperative, semantics of the preventive imperative, semantics of optativity, warning, threat, fear.

\section{Introduction}

\subsection{Actualizing the problem}

Preventive constructions have been sufficiently completely characterized both in grammatical and semantic research. However, a common approach to understanding of these utterances has not been developed.

A conventional point of view, being developed in the framework of grammatical theory, considers the preventive imperative as a type of semantics having as a means of its expression a specific type of syntactical constructions with negation, built by the form of the second person of perfective verbs in imperative mood. In accordance with this treatment, the term comprises a limited circle of constructions of the type: Не пролей!; Не поскользнись!; Не упади!, etc., having serious limitations of lexico-grammatical character. According to the conventional point of view, the prohibitive imperative and the preventive imperative form a semantically separate field of meanings in imperative speech, represented only with two meanings (Vinogradov, 1986). The difference between these sub-types of the stimulus with negation lies in the use of verb forms: prohibition is realized with imperfective verbs and prevention - with perfective verbs.

The semantics of the prevention only is in the centre of researchers' attention. Utterances with preventive imperatives are separated out without any support on the structural signs of the construction and its lexico-grammatical features. The preventive imperative, being separated out on the basis of its semantics, is not always clearly differentiated from prevention of danger or threat. Thus, means of the preventive imperative are analysed in close connection with the meanings of threat (Bezyaeva, 1992) and of fear (Dobrushina, 2006). L.A. Biryulin (Biryulin, 1992) also uses a semantic approach to the analysis of preventive constructions.

Thus, the relevance of the research is connected with a number of unsolved and debatable questions dealing with the interpretation of the language form of the analysed constructions and their meaning. 


\subsection{Hypothesis}

The preventive imperative as a type of semantics is of complex organization. It is a conglomerate of contiguous meanings creating a unique semantic image of the constructions which differentiate themselves on the background of semantically contiguous forms. The elements of imperative and indicative semantics, positive and contiguous related to them negative meanings are indivisibly united in the semantics of the preventive imperative.

\section{Materials and Methods}

In the present article we will hold to the conventional idea of this type of semantics, as we consider it to be more productive to reveal specific features of the preventive imperative and its differentiation from the contiguous constructions (with the meaning of caution, threat and fear) and also from prohibitive and optative constructions.

The descriptive method, based on the direct observation of language representations and their interpretations, is the leading method of the research where such techniques of linguistic analysis as transformations, translation into semantic meta-language, elements of pre-suppositional and component analysis are also used.

The research material is represented with colloquial speech, belles-letters, public relations texts, advertisements and nonfiction.

\section{Results}

\subsection{The preventive imperative as a type of syntactical structure}

According to the statements of grammatical theory, the meaning of the preventive imperative is expressed grammatically and has imperative constructions with the negation where only perfective verbs are used as means of expression. In accordance with this idea, the preventive imperative is not only a type of semantics but a type of syntactical constructions with lexico-grammatical limitations typical of them:

1) The predicate in the sentences of this kind is expressed only by a form of perfective verbs. Thus, V.S. Khrakovsky and A.P. Volodin (Khrakovsky, Volodin, 1986) determine preventive structures as structures of the type "не + an imperative form of a perfective verb". Due to this fact a close connection with a semantic content of the perfective verbs' aspectual forms is observed: the predicate denotes the action not in its process but in its result.

2) The predicate of preventive constructions denotes a non-purposeful action a realization or non-realization of which does not depend on the will of the recipient. The subject of the action is perceived as a passive participant of the process but not as the doer; he cannot initiate the beginning or the end of the process.

3) The action or condition is objectively viewed as negative (causing damage or loss), that is why the verbs with negative meaning are used as the predicate of the preventive imperative structures.

4) Semantics of the preventive imperative can be realized only in the form of a negative utterance.

A different opinion on the semantics of the preventive imperative and ways of its realization is introduced in current semantic trends. In semantic research any structure with or without $\mathrm{He}$ in which the recipient is warned about a threat is considered as preventive imperative: Берегись автомобиля!; Бойтесь данайцев, дары приносящих!; Осторожно: подделка, etc.

Sentences with the predicates denoting physical actions Не вставай!; Не сnешu!; Не болтай!; Не ходите cюda!, etc. are also interpreted as the ones having the meaning of warning. To express warning not only negative, but also positive structures are used: Уходите отсюда немедленно!; Беги отсюда!; Стой!, etc.

As a result, representatives of different trends come to completely opposite conclusions on the lexical means of realization of the semantics under discussion. "In the Russian language there is no special grammatical form to express this meaning..." (Dobrushina, 2006). "A negative imperative (prohibitive) usually produces the functions of the preventive imperative" (ibid).

In fact, a typical structure of imperative (inhibitive) sentences is used to express warning. However, the preventive imperative is a particular case of imperative structures, but it is not a type of grammatical meaning (as well as the prohibitive imperative), that is why no special form of grammatical mood to express warning is needed. 


\subsection{Semantics of the preventive imperative}

Preventive imperatives do not demand not to perform the action. Moreover, the recipient cannot perform it because of objective reasons. The form of the negative imperative of the second person denotes not the action which should not be performed, but something that might happen that serves to warn against it, care that is taken to avoid risks or danger. This fact determines a peripheral position of the preventive imperative in the system of imperative meanings (Kalinina, 2011; Kartashova, 2014a). Nevertheless, preventive imperatives do not belong to the class of "formally imperative", as V.Y. Gusev (Gusev, 2013) thinks. Not only the form of imperative constructions but their meaning is used in them. The elements of invariant semantics of stimulus are observed in preventive imperatives. Their aim is not only to warn the recipient of something unfavorable or dangerous but to make him avoid or prevent it. The semantic component 'try': 'try to avoid / prevent' can be elicited from preventive imperatives during their semantic interpretation. They contain care to avoid danger, be cautious, careful, attentive or demand making some efforts to prevent an undesirable action.

The degree of controlling the action can be various, that is why typical preventives contain caution, something that the recipient must be cautious of (cf.: Не заболей!; Не простудись!; Не поскользнись!), and in speech modifications something that the recipient must aim for. Cf.: Воду не пролей!; Не опрокинь!; Не разбей!; Не потеряй!; Не проспи!; Не опоздай!; Не навреди! (Doctor's commandment); He nponycmu бedy! (title of the article in the newspaper Argumenty i Facty).

Preventive constructions of this type denote the action that the recipient must not perform. They show that the preventive imperative is similar to the prohibitive imperative but the prohibitive imperative's meaning of such expressions is revealed on the background of the preventive imperative's meaning and is realized together with it. The connection with a typical semantics of the preventive imperative is explained by the fact that the recipient does not have any intention to perform the action the imperative denotes.

\subsection{The preventive imperative and the prohibition}

As it has been shown above, in some cases the preventive imperative is in maximal way close to the prohibitionpreventive. Nevertheless, the preventive imperative is a type of stimulus with the negation, which cardinally differs from the prohibition.

The term "preventive" used by V.S. Khrakovsky and A.P. Volodin (Khrakovsky, Volodin, 1986) emphasizes an important feature of the preventive imperative - a preventive character of this type of stimulus. The action denoted by the form of a perfective verb with the negation is foreseen by the speaker, it is considered by him as objectively possible but it is not performed in reality; the recipient does not perform and does not have any intention to perform this action. This feature distinguishes preventive imperatives from prohibitive imperatives aimed at prohibiting the action being performed or the intention to perform it. Thus, He nadaŭ! (prohibition) and He ynadu! (warning) denote the action being performed actually and the action which is possible to occur (potential).

Prohibitions and orders may be complicated by the meaning of warning and threat, "if, as consequences, some sanctions may be taken by the speaker toward the recipient" (Izotov, 1988). However, in the structures of the type He садись на этот стул; Не качайся на стуле (уnадешь), and also Не сnеши!; Не болтай!, in the sentences Не стой nод стрелой!; Не работай без уnора!, etc. warning of the danger does not have the main but the implicit co-meaning: Не садись на этот стул (а то упадешь). They directly denote the action to be avoided because of their consequences which are determined by the situations in which they are used, or they get an explicit realization in the second part of the complex sentence with the help of the construction being not the imperative sentence: Не влезай убьет! Cf.: Не ynaдu!; Не проболтайся!; Не промахнись!, etc. They directly denote the actions to be avoided because of bad consequences.

Preventive imperatives are directed at avoiding actions being not performed at the moment of speaking but quite possible. The utterance Не съешь все варенье!, given (in the book Typology of Imperative Structures, 1992) as an example of preventive structures does not meet this condition: the action is being performed by the recipient and it does not imply any consequences for him.

The preventive imperative is similar to the prohibition (in its preventive interpretation) and other types of stimulus with negations (advice and requests with negations) due to bad consequences in case the action is performed. In prohibitive utterances this direction explains the reason why it is necessary (or reasonable) to avoid performing the action, expressed by the imperative. In preventive utterances the relations between the stimulus itself (in its negative modifications) and its reasoning are presented as though being reversed. Cf.: Не беги так быстро! (you may fall down!) - He ynadu! (that is why do not run so fast); Закрой окно - простудишься (you may catch a cold) - He 
npocmyducb (that is why close the window).

Thus, the preventive imperative structures, in which the meaning of warning is the main, grammatically expressed one, are clearly enough distinguished from imperative and prohibitive sentences where the meaning of warning, caution is an accompanying, implicit component.

\subsection{Pragmatics of the Preventive Imperative}

The preventive imperative is not a call to perform the action expressed by the imperative, though sometimes it is interpreted as an indirect call either to perform the action or avoid doing some interstitial action (Gusev, 2013; Biryulin, 1992). According to V.Y. Gusev, the meaning of prevention is the result of two components: a) the speaker informs about an undesirable event $P ; b$ ) by his utterance the speaker tries to cause the listener or another person to perform an interstitial action $P_{\text {aux }}$ to prevent $P$ (i.e. to cause not-P) (Gusev, 2013).

This feature is not typical of all preventive constructions in the same degree, is not always observed and depends on contextual conditions of usage, on situational factor - on how actual danger is and on measures to prevent it. The preventive imperatives He nростудucb! (if the recipient is drinking cold water or is not wearing warm clothes); He обожгись! (if the recipient is near the fire or is drinking hot tea); Здесь высокий порог - не споткнись!, etc. can serve as an example. The prohibition to perform a definite action can be elicited from these structures: He ynadu! - He cmoŭ так близко к краю!; Отойди от огня!, which means that from the negative construction can be elicited both positive and negative imperative meanings. An indirect imperative meaning of these constructions is an area of implicit comeanings, a pragmatic constituent of the preventive imperative's semantics.

\subsection{Negation in the Structure of the Preventive Imperative Meaning}

In grammatical works preventive imperative utterances are the type of imperative structures with an obligatory negation (Kalinina, 2010). The negation is an inseparable component of not only a grammatical form, but also of the content of warnings and cautions. Unlike the prohibition, the preventive imperative does not have not only semantic but also grammatical correlate, i.e. correlative positive forms: *Упади!; *Ушибись!; *Простудись!, etc.

A preventive utterance cannot be interpreted as 'do not do P'. The negation нe in the preventive imperative construction does not serve to characterize the action expressed by the imperative either as undesirable or impermissible; it means that this negation is internal, not external. An internal negation is a component of propositional semantics belonging to the field of indicative meanings of the preventive imperative.

Positive and correlative meanings come into contact and cooperate in the semantics of the preventive imperative. They indirectly call to prevent the action denoted in the sentence; the call to counteract external circumstances can be interpreted in an absolutely opposite way expressed by the imperative: Не промахнись! = Постарайся попасть в цель!

Thus, preventive structures are naturally connected with the areas of both positive and negative meanings. According to V.Y. Gusev, the paradox of these constructions consists in the fact that Russian preventive structures with negativeness used in this grammatical form "can be used to prevent the action but not to prevent its negative performance" (Gusev, 2013). In addition, the paradox is that in a negative by its form construction there is reference not to the action that the recipient must do, but to the action that he must do - to avoid an undesirable situation or prevent the action being performed. Due to this fact they can be interpreted by the positive imperative utterance 'Do something to prevent $P^{\prime}$.

\subsection{Wish and Fear in the Structure of Preventive Meaning}

In preventive structures the action is denoted which cannot be performed without the recipient's conscious will. Practically nothing depends on the speaker's will, he cannot influence the situation favourably either for him or the recipient. A. Wierzbicka observes that "in a number of cases we warn people of something we consider inevitable, thus, trying to inform them at most of some future event and give them an opportunity to prepare for it" (Wierzbicka, 1985).

Due to the abovementioned reasons the imperative meaning in preventive structures is driven out from the sphere of will by correlative meanings, above all, by the meanings of wish and fear. The subject of preventive sentences expresses his wish to the recipient and wants the action not to be performed and fear that it may be performed. Fear is a reverse side of the wish containing negation. That is why in sentences with the semantics of prevention some kind of synthesis between the semantics of wish with the negation (cf.: И врагу этого не пожелаю) and fear is observed.

The meaning of the wish with the negation and closely connected with it emotions of fear are typical of utterances 
where a situation nominated in the sentence seems to be absolutely uncontrollable by participants of communication, and the threat of performing an undesirable action is only hypothetical. Cf.: He nростудись!; Не заблудись!, etc. (Kartashova, 2014b). In addition, not only the wish to avoid an undesirable situation is contained, as a rule, in preventive structures but also a stimulus to the recipient to prevent it, if possible.

\subsection{Warning and Threat in the Structure of the Preventive Imperative's Meaning}

The aim of preventive imperative structures is to warn the recipient about a possible, undesirable for him action (situation) expressed by the form of the imperative mood, so semantics of prevention is in a definite way connected with the meanings of warning (of danger) and threat. Prohibition, in its turn, contains the element 'prevention' ('I warn you about'...). However, in preventive constructions something that the recipient should be cautious of denotes the action expressed by the verb-predicate. Another difference lies in the fact that in typical preventive constructions danger, threatening to the recipient is considered as potential (possible), but by expressing the warning of danger this danger is quite real (visible).

In most cases the warning of danger gets an explicit utterance with the help of a notional lexical unit in the structures corresponding to structural features of declarative sentences: Минздрав предупреждает: курение опасно для вашего здоровья; Чрезмерное употребление алкоголя вредит вашему здоровью; in the structures where call for caution is expressed lexically: Берегись автомобиля; Осторожно: окрашено. Danger, the recipient should be cautious of is not notified in these sentences. Cf.: Не испачкайся!, where the warning of an undesirable act is expressed directly. The meaning of preventive constructions is not only the warning of danger. It has an imperative constituent - causation to avoid an undesirable situation.

The meaning of threat is expressed in the semantics of prevention as a kind of threat that an undesirable action, expressed by the imperative, can be performed - unlike the threat as the warning about undesirable consequences which may be resulted in sanctions by the addressor (direct threat) or the threat as possible bad consequences accompanying the meaning of direct stimulus or prohibition. An undesirable action itself (Не заболей; Не упади!), is in the center of attention in preventive constructions, it is in the action that contains danger for the recipient as a potential possibility of its realization.

The meaning of warning (about a potential realization of an undesirable action) and information about the threat of its realization are concurrent semes in the sentence structure. These two meanings have things in common. At the same time, the meaning of prevention has considerable differences from these correlative meanings both in the form of its realization and in content.

Thus, the preventive imperative as a type of semantics adjoins a number of correlative meanings such as wish, caution, warning and threat (as a threat of an undesirable action being performed). In one form or another, the preventive imperative contains in itself all these meanings as an undivided semantic complex. A form of the perfective verb with the negation is the center of all these meanings. It is what that differs preventive constructions from the sentences with a verbally expressed call for caution. Cf.: Берегись! - сказал Казбеку Седовласый Шат (M. Lermontov) - A.M. Peshkovsky's example (Peshkovsky, 2001). Cf.: Избегайте переохлаждения!; Остерегайтесь травм!, etc. All these meanings (Берегись!; Остерегайся!; Избегай!), etc. are implicit components in preventive constructions and they are not expressed by notional lexical units.

\section{Discussions}

The article suggests only one of the variants allowing solving a problem remaining highly debatable. Many questions concerning semantics, structure and functioning of preventive constructions ask for a deeper research. Thus, the problem of preventive structures' content variation causing important changes of typical semantics of the prevention has not been fully examined in the framework of the present article. Further research of the preventive imperative can be connected with the discussion how these constructions function in different types of discourse, for example, in advertising, where such utterances are relevant and frequently used (cf.: Не пропусти мировую премьеру!; Не дай себе засохнуть!), what a potential use of phraseologization of the preventive imperative's expressive means and semantic changes in the meaning of a linguistic form accompanying it is (cf.: Не вели казнить...; Не извольте беспокоиться; Не приведи бог, etc.). 


\section{Conclusion}

The prevention is not only a type of semantics. It is also a type of syntactical constructions, semantic variation of negative imperative utterances. This meaning, in its nature, is accompanied by a great number of concurrent meanings.

The semantic organization of preventive constructions is complex and contradictory. The prevention as a type of semantic content is a combination of correlative meanings (warning of danger, call for caution, wish that the action will not be realized and fear of its realization, call to avoid / prevent an undesirable action), forming an undivided semantic unity.

Variations of components' importance make it possible to develop in speech a specific side of their many-sided content by which a semantic diversity of constructions having a form of a preventive utterance is determined. The meaning of preventive constructions varies from good wish to physical prohibition with a great number of transitional stages between them, which, in its turn, depends on how a situation presented in the sentence is controlled and whether it is possible to prevent it.

The preventive imperative belongs to the type of marginal meanings in imperative speech because of many features. Imperative and indicative components, negative and positive meanings correlated with them are undividedly united in the preventive imperative's semantics.

Due to their peculiar features of expressing semantic content preventive constructions can serve as a means of indirect motivation either to perform or not to perform actions.

\section{References}

Bezyaeva, M.G. (2002). Semantics of the Speech Communicative Level: Expression of Will and the Speaker's Wish in the Russian Dialogue. Moscow: Moscow State University.

Biryulin, L.A. (1992). Theoretical Aspects of Semantic and Pragmatic Description of Imperative Utterances in the Russian Language: Abstract of Dissertation for Doctoral Degree in Philology. Saint-Petersburg.

Dobrushina, N.R. (2006). Grammatical Forms and Constructions with the Meaning of Prohibition and Prevention. Questions of Linguistics, 2, 28-67.

Gusev, V.Y. (2006). Typology of the Imperative. Moscow: Languages of the Slavonic Culture.

Izotov, A.I. (1998). Semantic Map of Imperativeness (Based on the Czhech and Russian Languages). Moscow: Philology.

Kalinina, A.A. (2010). The Prohibitive Imperative in the System of Prescriptive Meanings // Vestnik of the N.I. Lobachevsky Nizhny Novgorod University, 4 (2). N. Novgorod, 526-529.

Kalinina, A.A. (2011). The Category of Affirmation/Negation in the Functional Types of Sentences in the Modern Russian Language: Abstract of Dissertation for Doctoral Degree in Philology. Kazan.

Kartashova, E.P. (2014a). Creolized Text as Genre and Stylistic Phenomenon of the Russian Literature Modern at the Turn of the 20-21 Centuries. Current Problems of Science and Education, 6. [Online] Available: http//www.science-education.ru/120-1611 (13.12.2014).

Kartashova, E.P. (2014b). Aphorisms as a source of language expression in unique V.V Rozanov's style ."The Third International Congress on Social Sciences and Humanities". Proceedingsof the Congress (15 November, 2014). Volume 2. "East West" Association for Advanced for Advanced Studies and Highter Education GmbH. Vienna, 43-48.

Khrakovsky, V.S., Volodin, A.P. (1986). Semantics and Typology of the Imperative: The Russian Imperative. Leningrad: Nauka.

Peshkovsky, A.M. (2001). Russian Syntax in Scientific Research. Moscow: Languages of the Slavonic Culture. [Online] Available: http://www.twirpx.com/file/726010/ (May 4, 2015).

Typology of Imperative Constructions (1992). Khrakovsky (ed). Saint-Petersburg: Nauka.

Vinogradov, V.V. (1986). The Russian Language (Grammatical Teaching of the Word). (3rd ed.). Moscow: Languages of Slavic Culture. Wierzbicka, A. (1985). Acts of Speech. New Research in Foreign Linguistics. Issue XVI. Linguistic Pragmatics. Moscow, 251-275. 